\title{
Leaving high school: The influence and consequences for psychological well-being and career-related confidence
}

Authors:

\author{
Peter A. Creed ${ }^{1}$ \\ Juanita Muller ${ }^{1}$ \\ Wendy Patton ${ }^{2}$ \\ ${ }^{1}$ Griffith University - Gold Coast, Australia \\ ${ }^{2}$ Queensland University of Technology - Brisbane, Australia
}

Contact for correspondence:

Associate Professor Peter A. Creed

School of Applied Psychology

Griffith University (Gold Coast Campus)

PMB 50 Gold Coast Mail Centre

Queensland, Australia 4217

E-mail: p.creed@mailbox.gu.edu.au

Fax: +61 755528291 


\title{
Leaving high school: The influence and consequences for psychological well-being and career-related confidence
}

\begin{abstract}
This paper examines the well-being and career decision-making self-efficacy of adolescents before and after leaving school, and tests for the changes in these variables as a result of leaving school. While at high school, 309 students were assessed on levels of school achievement, well-being (psychological distress, self-esteem, life satisfaction) and career decision-making self-efficacy. Nine months after leaving school, 168 of these students completed the above surveys and measures of their access to the latent (e.g., social contact, time structure) and manifest (i.e., financial) benefits of employment, and work commitment. At T2, 21\% were full-time students, 35\% were full-time students who were also working part-time, $22 \%$ were employed in full-time jobs, and $21 \%$ were in the labour market but not employed full-time. These groupings were differentiated at T2 on aspects of well-being, self-efficacy, and access to the latent and manifest benefits of work, and at T1 on aspects of well-being and confidence. Leaving school improved well-being and confidence for some. One group was disadvantaged by having poorer well-being while at school, which predisposed them to disadvantage in the labour market. Results are discussed in relation to models of well-being and drift/social causation.
\end{abstract}


Adolescence can be marked by dramatic physiological and psychological changes. One transition point that can influence how adolescents handle these changes is the move from high school education to employment or post-secondary education. Society's expectation for 18-19 years olds is full-time employment, post-secondary school education or education and employment combined (Shanahan, Mortimer, \& Krueger, 2002). How adolescents manage this move from high school can either promote or impede their transition to adulthood. Two key issues at this transition point are psychological well-being and career decision-making self-efficacy.

\section{Well-being}

In relation to well-being, when adults in different occupational settings have been examined, restriction or loss of employment has been found to impact negatively on wellbeing (for a recent review, see Murphy \& Athanasou, 1999). For example, cross-sectional studies contrasting unemployed with employed people have identified higher levels of psychological distress (Waters \& Moore, 2002) and depression (Waters \& Moore, 2001), and lower levels of self-esteem (Muller, Hicks \& Winocur, 1993) in the unemployed groups. The evidence for adults loosely connected to the labour market (e.g., with part-time, casual or intermittent work) is that they also differ on level of well-being depending on their occupational status (Creed \& Machin, 2002).

The situation for young people is not as clear-cut. Several studies have found that adolescents who fail to engage in full-time employment after leaving school do not suffer psychological ill-health to the same extent as adults (Broomhall \& Winefield, 1990; Rowley \& Feather, 1987; see also Winefield, Tiggemann, Winefield \& Goldney, 1993). The explanations for this finding relate to adolescents having better financial and social support, and being able to accept being without a full-time paid job as being a more legitimate role. 
Despite this, adolescents without full-time paid work have been shown to have poorer wellbeing than adolescents who do. For example, results from a large-scale Australian study (Morrell, Taylor, Quine, Kerr, \& Western, 1994), based on the Australian Longitudinal Survey, found unemployed youth (15-24 years) to have poorer psychological health than their employed counterparts.

The most widely cited account to explain these differences in well-being across different occupational situations is Jahoda's (1981) latent deprivation model. Jahoda argued that employment conferred both manifest (associated with financial income) and latent (associated with meeting psychological needs) benefits on the person. People pursue employment to obtain manifest benefits, but while employed also gain from having five basic needs of time structure, social contact, common goals, status and enforced activity met. Loss or restriction of employment leads to a deprivation in both manifest and latent benefits, but it is the reduction in the latent benefits that operates to reduce well-being.

\section{Self-efficacy}

In relation to self-efficacy, Bandura's (1986) social cognitive theory proposed that an individual's beliefs and confidence in their ability to perform a given task influences their choices, performance and persistence on these tasks. Betz and Hackett (1986) established that college students' beliefs about their educational and career capabilities were significantly related to the range and type of career options they considered. High levels of career decision-making self-efficacy led students to increase participation in career decision-making tasks and behaviours, while low levels led them to avoid such activities. In this context, career decision-making self-efficacy reflects the career choice competencies that Crites (1961) proposed as relevant for the career decision-making process, those of 
accurate self-appraisal, gathering occupational information, goal selection, making plans for the future and problem solving.

A number of studies has identified career decision-making self-efficacy as a predictor of career exploration (Blustein, 1989), career maturity (Luzzo, 1995) and stability in the career patterns of college students (Gianakos, 1999). Several meta-analyses and reviews have also endorsed its utility (e.g., Betz \& Voyten, 1997; Hackett \& Lent, 1992). However, career decision-making self-efficacy research has been primarily focused on tertiary students and has been cross-sectional, thus failing to examine its developmental trajectory (Lent \& Hackett, 1987). In particular, there is little or no evidence as to the developmental path of career decision-making self-efficacy when students leave high school and enter the labour market or continue their formal education.

\section{Drift versus Social Causation}

A small number of longitudinal studies has tested whether the differential effects for well-being are related to the person (e.g., those with poorer well-being are more likely to become or remain unemployed) or the situation (i.e., it is aspects of the situation that influence well-being). The competing hypotheses here are known as "drift" (poor psychological well-being leads one to be more loosely connected to the labour market) and "social causation" (being loosely connected to the labour market leads one to develop poor psychological health; Dooley, Catalano \& Hough, 1992). While much of the evidence from longitudinal studies has indicated social causation as the determining factor (for a recent review, see Winefield, 1995), this issue has not been resolved (Hammarström \& Janlert, 1997). This is particularly so in the case where young people are involved. Creed (1999) for example, found that there was no evidence that young people with poor psychological wellbeing and poorly connected to the labour force were disproportionately disadvantaged in 
relation to gaining employment. However, this author did find that ability levels (both general and literacy) and length of unemployment were predisposing factors, with those less able and those unemployed longer doing more poorly in the labour market. While some attempts have been made to test the drift/social causation hypothesis in relation to wellbeing, this has not occurred in relation to the impact of career related variables, such as career decision-making self-efficacy.

\section{Present Study}

The present study tracks a cohort of terminating students from high school to nine months post-high school. The main foci are on well-being and career decision-making selfefficacy and the impact of the transition on these variables. First, the study will test Jahoda's latent deprivation model by examining the impact of access to the latent and manifest benefits across groups of school leavers who have different educational and occupational status, while controlling for their at-school levels. This is the first time a test of this model has been conducted while controlling for pre-existing variables. Consistent with Jahoda's predictions, it is expected that the post-school groups will differ on levels of latent and manifest benefits and well-being. Second, the study will test the impact of career decisionmaking self-efficacy across the same groups of school leavers, again while controlling for at-school levels. Consistent with social cognitive theory, it is expected that the greater exposure to occupational situations the more career decision-making self-efficacy will be experienced. Third, the study will test the drift/social causation hypothesis in relation to well-being and career decision-making self-efficacy by comparing scores prior to and after leaving high school. It is expected that students with low well-being and confidence levels while still at school will do poorer both psychologically and occupationally post-high 
school. As commitment to work has been identified as being influential in determining wellbeing in occupational settings (Feather, 1990) this variable will also be measured.

\section{Method}

\section{Participants}

At T1, participants were 309 final year high school students. Their ages ranged from $16.40-19.00$ years $(M=17.42, S D=.44)$, with $58 \%$ being female and $42 \%$ male, and $77 \%$ reporting paid work experiences outside of the school. On a self-report measure of school achievement, $8.9 \%$ indicated they typically achieved less than a satisfactory level at school (the six categories were $<\mathrm{SA}, \mathrm{SA}, \mathrm{SA}-\mathrm{HA}, \mathrm{HA}, \mathrm{HA}-\mathrm{VHA}$ and VHA, where SA = satisfactory, $\mathrm{HA}=$ high achievement and VHA = very high achievement), $24.7 \%$ indicated they typically achieved SA, 28.6\% achieved SA-HA, 19.6\% achieved HA, and 15.6\% achieved VHA or above.

At T2 (nine months after the students left school), 168 (54\%) of the original 309 students responded to a mail survey. The age range of these respondents was $17.30-19.50$ years $(M=$ $17.94, S D=.46$ ), with $65.40 \%$ female and $34.60 \%$ male. At T2, these 168 respondents had self-selected into the following groups: (i) 36 respondents $(21.30 \%)$ reported being full-time students with no paid work, (ii) 58 (34.90\%) reported being full-time students and working part-time, (iii) 38 (22.50\%) reported being employed full-time, (iv) 36 (21.30\%) reported being in the labour market but not employed full-time.

When those who dropped out of the study (completed T1 questionnaire only) were compared with those who remained in the study (completed T1 and T2 questionnaires), no differences were found on T1 scores on school achievement, career decision-making selfefficacy (CDMSE), psychological distress (GHQ-12), self-esteem (RSE), life satisfaction, whether they had work experience while at school, or age. Females were disproportionately 
more likely to respond at T2 than males, $\chi^{2}(1)=7.48, p<.01$. When males and females were examined separately, no differences were found between those who dropped out and those who remained in the study on $\mathrm{T} 1$ scores. Thus, minimal attrition bias was identified indicating that those responding at T2 differed little from the full sample at T1.

\section{Measures}

Career Decision-making Self-efficacy. The 25-item short version of the Career Decisionmaking Self-efficacy scale (CDMSE; Betz, Klein, \& Taylor, 1996a) was used to measure confidence regarding ability to make career-oriented decisions. A sample item is, "How confident are you that you could determine what your ideal job would be?". Participants rated their level of confidence on a 5-point scale, with end-points of "no confidence at all" to "complete confidence". Higher scores indicate more career-related confidence. Betz et al. (1996b) reported adequate validity for the scale, and indicated satisfactory internal reliabilities ranging from .73 to .83 . The internal reliability coefficients for the present study were .93 at $\mathrm{T} 1$ and .92 at $\mathrm{T} 2$.

Psychological Distress. The 12-item version of the General Health Questionnaire (GHQ12; Goldberg, 1972) was used to measure psychological distress. This version has been recommended by Banks et al. (1980) for use in occupational studies, and has been used extensively by researchers in this area (e.g., Warr, 1987). Participants were asked to report on how they felt recently on a range of variables, including cognitive processing, self esteem, anxiety and depression (e.g., "Have you recently been able to concentrate on whatever you're doing?"). Responses were scored on a four-point scale (0-3) that used anchors such as "better than usual/same as usual/less than usual/much more than usual". Higher scores indicated more psychological distress. Goldberg and Williams (1988) 
reported a mean internal consistency of .85 . Internal reliability for the present study was .84 at $\mathrm{T} 1$ and .80 at $\mathrm{T} 2$.

Self-esteem. The 10-item Rosenberg Self-esteem scale (RSE; Rosenberg, 1965) was used to provide a measure of global evaluation of self worth. The RSE is the most widely used instrument for the measure of this construct (Blascovich \& Tomaka, 1991). Participants are asked to respond by rating how strongly they agree with each statement on a four-point scale, using end-points of "strongly agree" and "strongly disagree". Answers were scored from 1-4, giving a possible range of 10-40, with higher scores indicating lower self-esteem. The internal reliability coefficient for this sample was .88 at $\mathrm{T} 1$ and .89 at $\mathrm{T} 2$.

Life Satisfaction. A one-item measure of Life Satisfaction (LS) was utilised to provide a measure of context-free global well-being. Participants were asked to indicate when they looked at their life how satisfied they were. Responses were recorded on a four-point scale ranging from "very satisfied" to "not satisfied", with higher scores indicating less satisfaction.

Work Commitment. Six items from the eight-item Work Commitment scale (WC; Rowley \& Feather, 1987) were administered at T2 to gain a measure of participants' commitment to being in the labour market. Two items from the scale were not included as they referred specifically to participants being unemployed and not to the full range of participants being surveyed (e.g., "I really must get a job or lose my self-respect"). Participants were asked to indicate how strongly they agreed with a series of statements (e.g., "Even if I won a great deal of money in the lottery, I would want to continue working somewhere") on a five-point scale that used end-points of "disagree a lot" and "agree a lot". Item scores were totalled to give a global rating, with higher scores representing a stronger commitment. Rowley and Feather reported an internal reliability for the full scale of .85 
with an unemployed sample. The internal reliability coefficient calculated for this study at T2 was .74.

Latent Benefits of Employment. The 15-item Access to Categories of Experience (ACE) scale (ACE; Evans, 1986) was used to measure access to the latent benefits of employment. The ACE scale asks questions related to the five latent benefits (e.g., for time structure, "My time is filled with things to do"; for social contact, "Most days I meet quite a range of people"). Participants indicate their agreement with the items on a seven-point scale using endpoints of "completely disagree" and "completely agree". Higher scores indicate greater access to the latent benefits. Evans and Banks (1992) reported adequate reliability levels for the ACE when used with a large unemployed sample, and presented content validity evidence based on factor analysis. The internal reliability calculated at T2 was .76.

Financial Strain. Three questions, based on items previously used with occupational samples were utilised to tap financial strain (FS; Warr \& Jackson, 1987). The three questions were: "How easy or difficult is it to manage on the money you receive?", "Do you find that a shortage of money stops you engaging in activities?", and "Do you ever feel that you have to refuse invitations from your friends through not having enough money?". Participants were asked to respond on a five-point scale, with anchors such as "very often/quite often/uncertain/very rarely/never”. Higher scores indicated more financial strain. The internal reliability calculated at T2 was .73.

\section{Procedure}

The data reported here constitute the second phase of a larger study that examined aspects of career development for high school age students. In the first phase (Patton \& Creed, 2001), cross-sectional analyses examined correlates of career maturity and career indecision in a large sample of high school students across Grades 8-12. The present study 
reports outcomes for the Grade 12 students only, who were assessed on a second occasion after they had left high school. At T1, the students' classroom teachers, who had been provided with instructions regarding the testing protocol, administered the survey forms. At $\mathrm{T} 2$, nine months after leaving school, the students were surveyed by mail. Every effort was made to reduce the $\mathrm{T} 2$ attrition rate from the study. At follow-up, all students were posted an initial letter and questionnaire. Those who did not return this questionnaire were sent a reminder letter and another questionnaire. Those who did not respond to this reminder were contacted by telephone (where available from the T1 survey) and encouraged to continue with their participation. No rewards were given for participation.

Three Australian high schools participated in the project. While not randomly selected, the schools can be considered typical of coeducational institutions situated in suburban Australia. Two schools were State funded: one was situated in a low socioeconomic area and the second in a middle-high area. The third school was a private denominational school that charged modest school fees and attracted a wide socioeconomic range of students. The project also constituted school-based careers' audits for the participating schools; consequently all students participated in the evaluation.

\section{Results}

\section{Summary Statistics}

Summary data and bivariate correlations are presented in Table 1 for $\mathrm{T} 1$ and $\mathrm{T} 2$ variables. When gender was examined no significant differences were identified between males and females on any of the variables at $\mathrm{T} 1$ or $\mathrm{T} 2$, except that at $\mathrm{T} 1$ girls reported higher levels of school achievement than boys, $t(143)=3.21, p<.01$. 
Table 1

Means, standard deviations and bivariate correlations for variables at $T 1$ and T2; $(N=309$ at $T 1, N=168$ at T2).

\begin{tabular}{|c|c|c|c|c|c|c|c|c|c|c|c|c|c|c|c|}
\hline Variables & $n^{\#}$ & $M$ & $S D$ & 1 & 2 & 3 & 4 & 5 & 6 & 7 & 8 & 9 & 10 & 11 & 12 \\
\hline \multicolumn{16}{|l|}{$T 1$} \\
\hline 1. CDMSE & 206 & 88.14 & 17.66 & - & $-.36 * * *$ & $-.45 * * *$ & $-.26 * * *$ & $.38 * * *$ & $.46 * * *$ & -.17 & $-.39 * * *$ & -.16 & $.32 * *$ & -.03 & $.27 * *$ \\
\hline 2. GHQ-12 & 285 & 12.85 & 5.71 & & - & $.52 * * *$ & $.43 * * *$ & -.05 & $-.32 * * *$ & $.30 * * *$ & $.25 * *$ & $.21 *$ & -.16 & $.24 * *$ & -.10 \\
\hline 3. $\mathrm{RSE}$ & 287 & 20.66 & 5.60 & & & - & $.49 * * *$ & $-.23 * * *$ & $-.31 * * *$ & $.25 * *$ & $.39 * * *$ & $.32 * * *$ & $-.24 * *$ & .06 & -.09 \\
\hline 4. LS & 293 & 2.02 & 0.90 & & & & - & $-.19 * *$ & $-.24 * *$ & $.19 *$ & $.22 * *$ & $.30 * * *$ & $-.25 * *$ & $.19^{*}$ & -.12 \\
\hline 5. $\mathrm{SA}$ & 280 & 6.16 & 1.41 & & & & & - & .12 & .03 & -.06 & $-.19 *$ & $.19 *$ & .05 & $.17 *$ \\
\hline \multicolumn{16}{|l|}{$T 2$} \\
\hline 6. CDMSE & 168 & 89.35 & 14.90 & & & & & & - & $-.28 * * *$ & $-.39 * * *$ & $-.38 * * *$ & $.39 * * *$ & $-.19 *$ & $.29 * * *$ \\
\hline 7. GHQ-12 & 168 & 11.38 & 4.61 & & & & & & & - & $.62 * * *$ & $.39 * * *$ & $-.35 * * *$ & $.28 * * *$ & -.09 \\
\hline 8. RSE & 168 & 19.76 & 5.11 & & & & & & & & - & $.32 * * *$ & $-.47 * * *$ & .13 & $-.20 *$ \\
\hline 9. LS & 168 & 2.20 & 0.75 & & & & & & & & & - & $-.39 * * *$ & $.20 * *$ & -.13 \\
\hline 10. ACE & 167 & 74.54 & 10.77 & & & & & & & & & & - & $-.27 * * *$ & $.28 * * *$ \\
\hline 11. FS & 168 & 8.99 & 2.92 & & & & & & & & & & & - & $-.19 *$ \\
\hline 12. WC & 167 & 35.04 & 5.15 & & & & & & & & & & & & - \\
\hline
\end{tabular}

Note: CDMSE = Career decision-making self-efficacy, GHQ-12 = psychological distress (General Health Questionnaire), RSE $=$ self-esteem (Rosenberg Self-esteem Scale), LS = Life satisfaction, SA = School achievement, ACE = latent benefits of employment (Access to Categories of Experience Scale), $\mathrm{FS}=$ Financial strain, $\mathrm{WC}=$ Work commitment. $*=p<.05, * *=p<.01, * * *=p<.001$. 
Significant, meaningful correlations $(r \geq .32$, where the shared variance is greater than 10\%; Tabachnik \& Fidell, 1996) were examined from Table 1. Career decision-making selfefficacy (CDMSE) at T1 was correlated with psychological distress (GHQ-12), self-esteem (RSE) and school achievement (SA) at T1 (indicating the higher the efficacy at T1, the lower the distress, the higher the self-esteem and the better school achievement at T1). CDMSE at T1 was also associated with CDMSE, RSE and the latent benefits (ACE) at T2 (indicating the higher the efficacy at $\mathrm{T} 1$, the higher the self-esteem and access to the latent benefits of employment at T2). CDMSE at T2 was associated with RSE, LS and ACE at T2 (indicating the higher the efficacy at T2, the higher the self-esteem and life satisfaction, and the better the access to the latent benefits of employment at T2).

Psychological distress (GHQ-12) at T1 was associated with RSE and LS at T1 (indicating the less distress at $\mathrm{T} 1$, the higher the self-esteem and life satisfaction at $\mathrm{T} 1$ ). GHQ-12 at T1 was also associated with CDMSE at T2 (indicating the less distress at T1, the more efficacy at T2). GHQ-12 at T2 was associated with RSE, LS and ACE at T2 (indicating the less distress at $\mathrm{T} 2$, the more self-esteem, life satisfaction and access to the latent benefits at T2). Self-esteem (RSE) at T1 was associated with CDMSE, GHQ-12 and LS at T1 (indicating the more self-esteem at T1, the more efficacy and life satisfaction, and the less distress at T1). RSE at T1 was also associated with RSE and LS at T2 (indicating the higher self-esteem at T1, the more self-esteem and life satisfaction at T2). RSE at T2 was associated with CDMSE, GHQ-12, LS, and ACE at T2 (indicating the more self-esteem at T2, the more efficacy, life satisfaction and access to the latent benefits of employment, and the less distress at T2). Life satisfaction at T1 was associated with GHQ-12 and RSE at T1 (indicating the high life satisfaction at T1, the more self-esteem and the less distress at T1). LS at T1 was not meaningfully associated with any variables at T2. LS at T2 was associated with CDMSE, GHQ-12, RSE and ACE at T2 (indicating the more life 
satisfaction at $\mathrm{T} 2$, the higher efficacy, self-esteem and access to the latent benefits, and the less distress at $\mathrm{T} 2$ ).

Occupational Status Comparisons at T2

Participants at T2 self-selected into one of four categories: (i) full-time students, (ii) fulltime students who were working part-time, (iii) employed full-time, and (iv) in the labour market but not employed full-time. One-way ANOVA and chi-square tests confirmed that these four groups did not differ on the demographic variables of age or gender. A between subjects MANOVA was used to test for differences across the four conditions on the career (career decision-making self-efficacy, work commitment, access to the latent benefits of employment, financial strain) and well-being (psychological distress, self-esteem, life satisfaction) related variables. Significant univariate effects were identified for three of the four career-related variables, of career decision-making self-efficacy, $F(3,162)=2.76, p<$ .05 , access to the latent benefits of employment, $F(3,162)=4.10, p<.01$, and financial strain, $F(3,162)=2.72, p<.05$, and one of the well-being related variables, of life satisfaction, $F(3,162)=4.98, p<.01$. Post-hoc Tukey HSD tests for career decisionmaking self-efficacy indicated that the full-time employed had significantly higher levels of efficacy than those in the labour market but not full-time employed $(p<.05)$. For the latent benefits, the full-time employed had significantly greater access than the full-time students $(p<.01)$. For financial strain, the full-time employed had significantly less strain than the full-time students $(p<.05)$. For life satisfaction, the full-time students $(p<.01)$, full-time students with paid work $(p<.05)$ and full-time employed $(p<.01)$ all reported significantly higher levels than those in the labour market without full-time paid work. Summary data are presented in Table 2. 
Table 2

Means and standard deviations for career and well-being related variables at T2 for categories of full-time students, full-time students and working part-time, employed full-time, and labour market but not full-time employed; $N=168$.

\begin{tabular}{|c|c|c|c|c|c|c|c|c|c|c|c|c|c|c|c|}
\hline \multirow[b]{2}{*}{ Variable } & \multicolumn{3}{|c|}{ F/T Students } & \multicolumn{3}{|c|}{ F/T Students + Work } & \multicolumn{3}{|c|}{ F/T Employed } & \multicolumn{3}{|c|}{ Not F/T Employed } & \multicolumn{3}{|c|}{ Total T2 } \\
\hline & $\underline{n}^{\#}$ & $M$ & $S D$ & $n$ & $M$ & $S D$ & $n$ & $M$ & $S D$ & $n$ & $M$ & $S D$ & $n$ & $M$ & $S D$ \\
\hline CDMSE & 34 & 88.21 & 13.14 & 58 & 89.97 & 16.21 & 38 & 93.55 & 14.06 & 36 & 83.97 & 13.77 & 166 & 89.13 & 14.85 \\
\hline $\mathrm{WC}$ & 34 & 33.35 & 5.88 & 58 & 34.83 & 5.33 & 38 & 36.42 & 4.72 & 36 & 35.33 & 4.17 & 166 & 35.00 & 5.14 \\
\hline $\mathrm{ACE}$ & 34 & 70.06 & 11.17 & 58 & 75.29 & 9.21 & 38 & 78.47 & 9.59 & 36 & 73.31 & 12.58 & 166 & 74.52 & 10.80 \\
\hline $\mathrm{FS}$ & 34 & 9.97 & 3.18 & 58 & 9.16 & 2.67 & 38 & 8.08 & 2.80 & 36 & 8.81 & 2.93 & 166 & 9.00 & 2.91 \\
\hline GHQ-12 & 34 & 10.85 & 3.74 & 58 & 12.05 & 4.42 & 38 & 10.29 & 4.55 & 36 & 12.25 & 5.45 & 166 & 11.45 & 4.60 \\
\hline RSE & 34 & 20.41 & 4.60 & 58 & 19.57 & 5.43 & 38 & 19.00 & 4.88 & 36 & 20.56 & 5.30 & 166 & 19.83 & 5.10 \\
\hline LS & 34 & 2.06 & 0.65 & 58 & 2.16 & 0.79 & 38 & 2.03 & 0.75 & 36 & 2.61 & 0.69 & 166 & 2.20 & 0.76 \\
\hline
\end{tabular}

Note: Refer Table 1 for legend. " Sample sizes differ as not all participants completed all parts of the survey. 
A second analysis was conducted in this section to test for differences across the four conditions while controlling for the $\mathrm{T} 1$ variables of career decision-making self-efficacy, psychological distress, self-esteem and life satisfaction, which were correlated with these dependent variables at T2. This MANCOVA utilised 108 participants (a subset of the 168 participants used in the first analysis) who had completed all survey scales at T1 and T2. Chi-square analyses and one-way ANOVAs indicated that these 108 participants did not differ significantly from the full group of 168 on gender or group composition, or on any of the $\mathrm{T} 1$ or $\mathrm{T} 2$ variables, indicating that no selection bias was identified. Only one significant univariate effect was identified from this MANCOVA. This was for the variable of life satisfaction, $F(3,100)=3.36, p<.05$, with the full-time students, full-time students with paid work and full-time employed all reporting higher levels than those in the labour market without full-time paid work. Trend differences $(p<.10)$ remained for the variables of career decision-making self-efficacy and self-esteem, but not for access to the latent benefits. The results from this section indicate that the four groups initially did differ on the variables of career decision-making self-efficacy, access to the latent benefits of employment, financial strain and life satisfaction, however, these significant differences, apart from those associated with life satisfaction, disappeared when the T1 variables were controlled.

\section{Comparisons of groups at $T 1$}

This section examined the four occupational status categories retrospectively to determine if there were differences in the groups on the variables being examined prior to leaving school. A significant chi-square analysis, $\chi^{2}(3)=10.11, p<.05$, indicated that at T1 only $56 \%$ of those who were full-time students at $\mathrm{T} 2$ reported paid work while still at school. The percentages for paid work experience at $\mathrm{T} 1$ for those who were full-time students with paid work, employed full-time, and in the labour market but not employed at T2, were $83 \%, 68 \%$ and $81 \%$ respectively. Because of the differing sample sizes for the 
dependent variables, one-way ANOVAs were used to test for differences among the four groups at T1. As five ANOVAs were conducted, a more conservative alpha level, based on a Bonferroni adjustment, of $p<.01$ was set for each analysis. These analyses revealed a significant group effect for the school achievement variable, $F(3,142)=5.12, p<.01$. The well-being variable of psychological distress approached significance using this criterion, $F(3,141)=3.07, p=.03$. Post-hoc Tukey HSD tests indicated that for school achievement, full-time students with paid work at T2 reported higher levels of achievement at T1 than both the full-time employed $(p<.01)$ and those in the labour market without full-time work $(p<.05)$ at T1. For psychological distress, which approached significance, the full-time students with paid work $(p<.01)$ and the full-time employed at T2 reported lower levels $(p$ $<.05)$ at $\mathrm{T} 1$ than those in the labour market without full-time work. Summary data are presented in Table 3.

\section{Comparison between groups T1-T2}

This analysis compared the four occupational status categories between T1-T2 to determine if moving from school resulted in changes in the career related or well-being variables. Because of the differing sample sizes for the four dependent variables, individual repeatedmeasure t-tests were used to test for differences between $\mathrm{T} 1$ and $\mathrm{T} 2$. As four t-tests were conducted for the total sample, a more conservative alpha level, based on a Bonferroni adjustment, of $p<.015$ was set. As a total group, moving from school to post-school settings resulted in a significant reduction in psychological distress and an improvement in self-esteem. There was no change for career decision-making self-efficacy or life satisfaction, although there was a trend $(p<.05)$ indicating a decline in life satisfaction. When the individual sub-groups were examined, there was a significant (alpha level set at .015) reduction in psychological distress and an improvement in career decision-making self-efficacy for the full-time students at T2. A number of trends $(p<.05)$ were also 
Table 3

Mean and standard deviation scores for career and well-being related variables at T1 for those who were full-time students, full-time students working part-time, employed full-time, and those in the labour market but not full-time employed at T2.

\begin{tabular}{|c|c|c|c|c|c|c|c|c|c|c|c|c|c|c|c|}
\hline \multirow[b]{2}{*}{ Variable } & \multicolumn{3}{|c|}{ F/T Students } & \multicolumn{3}{|c|}{ F/T Students + Work } & \multicolumn{3}{|c|}{ F/T Employed } & \multicolumn{3}{|c|}{ Not F/T Employed } & \multicolumn{3}{|c|}{ Total } \\
\hline & $n^{\#}$ & $M$ & $S D$ & $n$ & $M$ & $S D$ & $n$ & $M$ & $S D$ & $n$ & $M$ & $S D$ & $n$ & $M$ & $S D$ \\
\hline CDMSE & 23 & 82.43 & 13.90 & 40 & 93.85 & 19.98 & 25 & 87.68 & 18.97 & 25 & 85.48 & 15.40 & 113 & 88.31 & 18.02 \\
\hline GHQ-12 & 29 & 13.66 & 4.81 & 51 & 11.92 & 5.94 & 36 & 11.53 & 6.21 & 29 & 15.24 & 5.03 & 145 & 12.83 & 5.75 \\
\hline $\mathrm{RSE}$ & 29 & 21.28 & 4.91 & 52 & 19.60 & 5.99 & 36 & 20.86 & 4.28 & 30 & 22.73 & 1.11 & 147 & 20.88 & 5.50 \\
\hline LS & 32 & 2.23 & 1.02 & 54 & 1.85 & 0.88 & 36 & 1.86 & 0.87 & 31 & 2.16 & 0.78 & 153 & 2.00 & 0.90 \\
\hline SA & 32 & 6.23 & 1.29 & 53 & 6.75 & 1.21 & 33 & 5.79 & 1.36 & 28 & 5.84 & 1.33 & 146 & 6.25 & 1.34 \\
\hline
\end{tabular}

Note: Refer Table 1 for legend. ${ }^{\#}$ Sample sizes differ as not all participants completed all parts of the survey. 
identified. For those who continued as full-time students with part-time work, there was a trend towards a decline in life satisfaction. For those who ended up in the labour market without full-time work, there was a trend towards a decline in psychological distress, an improvement in self-esteem, and a decline in life satisfaction. There was no change in any variable for the full-time employed (Summary data are presented in Table 4).

As manipulation checks, follow-up analyses were utilised in this section, using repeatedmeasures MANOVAs, and conducted on the 108 participants who completed all $\mathrm{T} 1$ and $\mathrm{T} 2$ survey scales of career decision-making self-efficacy, psychological distress, self-esteem and life satisfaction. Consistent with the t-tests conducted above, significant time effects were identified on the variables of psychological distress, $F(1,107)=5.22, p<.05$, and self-esteem, $F(1,107)=6.39, p<.05$. The same trend $(p<.10)$ towards lower life satisfaction was also identified. For the full-time students, there was a significant reduction in psychological distress, $F(1,22)=8.64, p<.01$, and an improvement in career decisionmaking self-efficacy, $F(1,22)=10.49, p<.01$. For the full-time students with paid work, there was a significant decline in life satisfaction, $F(1,38)=4.45, p<.05$. For those who ended up in the labour market without full-time work, there was a significant improvement in self-esteem, $F(1,21)=4.76, p<.05$, and life satisfaction, $F(1,21)=6.41, p<.05$. Lastly, there were no changes on any variable for the full-time employed. 
Table 4

Mean and standard deviation scores for career and well-being related variables at T1 and T2 for categories of full-time students, full-time students and working part-time, employed full-time, and in the labour market without full-time work.

\begin{tabular}{|c|c|c|c|c|c|c|}
\hline \multirow[b]{2}{*}{ Category } & \multicolumn{3}{|c|}{$\mathrm{T} 1$} & \multicolumn{3}{|c|}{$\mathrm{T} 2$} \\
\hline & $n^{\#}$ & $M$ & $S D$ & $M$ & $S D$ & $t$ \\
\hline \multicolumn{7}{|c|}{ Full-time student } \\
\hline CDMSE & 23 & 82.43 & 13.90 & 90.96 & 12.85 & $-3.24 * *$ \\
\hline GHQ-12 & 29 & 13.66 & 4.81 & 10.45 & 3.68 & $3.63^{* *}$ \\
\hline RSE & 29 & 21.28 & 4.91 & 19.62 & 4.81 & 1.61 \\
\hline LS & 32 & 2.23 & 1.02 & 2.03 & 0.65 & 0.98 \\
\hline \multicolumn{7}{|c|}{ Full-time student $+p / t$ work } \\
\hline CDMSE & 40 & 93.85 & 19.98 & 89.98 & 16.75 & 1.37 \\
\hline GHQ-12 & 50 & 12.02 & 5.95 & 11.84 & 4.34 & 0.22 \\
\hline RSE & 51 & 19.78 & 5.90 & 19.43 & 5.45 & 0.44 \\
\hline LS & 53 & 1.87 & 0.88 & 2.15 & 0.79 & $-2.45^{*}$ \\
\hline \multicolumn{7}{|c|}{ Full-time employed } \\
\hline CDMSE & 25 & 87.68 & 18.97 & 94.32 & 13.05 & -1.66 \\
\hline GHQ-12 & 36 & 11.53 & 6.21 & 10.58 & 4.39 & 0.82 \\
\hline RSE & 36 & 20.86 & 4.28 & 19.22 & 4.91 & 1.74 \\
\hline $\mathrm{LS}$ & 36 & 1.86 & 0.87 & 2.06 & 0.75 & -1.36 \\
\hline \multicolumn{7}{|c|}{ Labour market without f/t work } \\
\hline CDMSE & 25 & 85.48 & 15.40 & 83.40 & 12.79 & 0.77 \\
\hline GHQ-12 & 29 & 15.24 & 5.03 & 12.28 & 5.83 & $2.33^{*}$ \\
\hline RSE & 30 & 22.73 & 6.10 & 20.27 & 5.50 & $2.08 *$ \\
\hline LS & 31 & 2.16 & 0.78 & 2.61 & 0.72 & $-2.37 *$ \\
\hline \multicolumn{7}{|l|}{ Total } \\
\hline CDMSE & 113 & 88.31 & 18.02 & 89.68 & 14.68 & -0.85 \\
\hline GHQ-12 & 144 & 12.88 & 5.75 & 11.33 & 4.59 & $3.00 * *$ \\
\hline RSE & 146 & 20.95 & 5.45 & 19.59 & 5.17 & $2.82 * *$ \\
\hline LS & 152 & 2.00 & 0.90 & 2.20 & 0.76 & $-2.43^{*}$ \\
\hline
\end{tabular}

Note: Refer Table 1 for legend. ${ }^{\#}$ Sample sizes differ as not all participants completed all parts of the survey. $*=p<.05, * *=p<.015$.

\section{Discussion}

Occupational Status Comparisons at T2

On leaving school, the students self-selected into one of four occupational groupings. At $\mathrm{T} 2$, these four groups differed significantly on levels of career decision-making self- 
efficacy, access to the latent benefits of employment, financial strain and levels of life satisfaction. Based on the group means, the students who were full-time employed at T2 consistently reported better scores than the other groups. They reported higher levels of career decision-making self-efficacy, more access to the latent benefits of employment, less financial strain and higher levels of life satisfaction. The students at T2 who were most disadvantaged were those in the labour market without full-time employment (the least career decision-making self-efficacy and lowest life satisfaction) and the full-time students without employment (the least access to the latent benefits of employment and the highest financial strain).

Specifically for access to the latent benefits of employment, mean scores were highest for the full-time employed, and then in order, the full-time students with part-time work, those in the labour force but not in full-time work, and lastly the full-time students. There was a significant difference in means between the full-time employed and the full-time students. These results indicate some consistency with reported outcomes from other studies that compared employed and unemployed adults (Waters \& Moore, 2002), employed and unemployed youth (Evans \& Haworth, 1991) and unemployed and underemployed adults (Creed \& Machin, 2002), with the greatest access to the latent benefits resulting from fulltime work and the least from full-time education. These results are consistent with the predictions of the latent deprivation model. Jahoda (1982) argued that while other social institutions (e.g., the family, education) may allow some of the latent benefits to be provided, none do so in combination with "as compelling a reason as earning one's living" (p. 59). The implication is that post-secondary educational institutions may not meet the psychological needs of young people in the same way that paid work does. Leaving high school and entering different occupational settings has implications for the levels of access to the benefits that come from working. 
A similar picture emerged for financial strain. Those in full-time work at $\mathrm{T} 2 \mathrm{had}$ the lowest mean scores for financial strain, followed by those in the labour force without fulltime work, the full-time students with paid work, and lastly, the full-time students. Again, there was a significant difference between the full-time employed and the full-time students. Despite suggestions that many recent school-leavers would still be receiving financial support from the family, whether they were living at home or independently (Broomhall \& Winefield, 1990), the evidence from this analysis is that the post-secondary school pathway chosen by high school students has an influence on how this stressor is experienced.

For career decision-making self-efficacy, highest scores were reported by the full-time employed group, followed by the two student groups, and lastly, those in the labour market without full-time work. There was a significant difference between the full-time employed and those in the labour market without full-time work. Low levels of career decisionmaking self-efficacy have been theorised to lead to low levels of participation in career decision-making tasks and behaviours, such as career-related self-appraisal, seeking occupational information, goal setting, planning for the future, and problem solving (Betz \& Hackett, 1986; Betz \& Klein, 1997). Those in the labour market without full-time work were disadvantaged regarding these particular confidences.

In relation to psychological well-being, the four groups differed on levels of life satisfaction, with the full-time employed reporting the highest life satisfaction, followed in turn by the full-time students, the full-time students with paid work, and those in the labour force without full-time work. Those in the labour force without full-time work reported significantly lower life satisfaction than all three other groups. The latent deprivation model would predict well-being differences based on different occupational experiences that reflect different levels of access to the latent benefits of employment. These results are consistent with these predictions. Others (e.g., Whelan, 1992) have also identified levels of 
well-being varying in response to perceived and actual reports of poverty, meaning that these results for life satisfaction are consistent with the findings for financial strain.

Lastly, regarding work commitment, despite evidence that it not a stable characteristic (Banks \& Henry, 1993) and that differences do exist between employed and unemployed individuals (Feather \& O'Brien, 1986), no significant differences were found among the four groups examined. Further, all groups had high means indicating that at this early stage in the transition from school-to-work there was a strong work commitment by all groups.

In conclusion, it can be said that nine months after leaving high school the group that appears to be the most advantaged are those in full-time employment. This group reported the greatest access to the latent benefits of employment, the least financial strain, the highest levels of career decision-making self-efficacy and the highest levels of life satisfaction. The implication here is that these gains, while they may be related to short-term occupational goals (i.e., immediate gains from the labour market rather than investing more time and money in occupational training), are likely to act as an incentive for this particular schoolto-work pathway. Confounding these outcomes and conclusions is the finding that the differences between the groups on the latent benefits of employment, financial strain and career decision-making self-efficacy (but not life satisfaction) disappeared when the T1 variables were controlled for. The important evidence here is that pre-existing psychological states also play a role in the perceptions of latent environmental benefits (social support, time structure, activity level, collective purpose and status), perceived financial strain and career decision-making confidence. This is likely to reflect both a social causation effect (where the situation is impacting on perceptions of the environment) and a drift effect (where pre-existing features predispose a student towards a particular environment). Consistent with this explanation, Creed and Evans (In press) have demonstrated that the latent benefits are associated with personality and that personality influences the association 
between access to the latent benefits and well-being. The implication here for the latent deprivation model (Jahoda, 1982) is that pre-existing predispositions need to be included in this account of access to the latent and manifest benefits of employment and well-being.

\section{Longitudinal Analysis}

Firstly, the experience of leaving school resulted in well-being benefits when the entire sample was considered, with a significant reduction in psychological distress and a significant improvement in self-esteem; although there was a trend towards a reduction in life satisfaction. This is consistent with other studies that have identified self-esteem improvements when young people leave school (Gurney, 1980; Winefield \& Tiggemann, 1985), even if the young people end up becoming unemployed (Winefield \& Tiggemann, 1985). A recent cross-sectional analysis has indicated an increase in the reporting of psychological distress as students progress through the high school years (Patton \& Creed, 2001). The final year of high school may be particularly distressing because of the range of demands placed on students at this stage in their life (e.g., academic, social and career decision-making). Leaving school may reduce these demands, which may account for the improvement in well-being in the short-term (e.g., academic pressure is lessened, career decisions have been made). However, leaving school may also bring other pressures that lead school-leavers to view their post-school situations as less satisfying than their school experience (such as not having access to a ready social network).

These across-time well-being changes for the entire sample reflected changes for three of the four post-school groupings, namely the students who went on to post-secondary fulltime study (reduction in psychological distress), students who went into the labour market but were not working full-time (trends for reduction in psychological distress, improvement in self-esteem, and a decline in life satisfaction), and students who continued as full-time 
students but were engaged in part-time work (trend for a decline in life satisfaction). No well-being changes were reported for the students who were full-time employed. For career decision-making self-efficacy, no change was identified when the cohort was examined as a whole, although there was a trend towards an improvement after leaving high school for the full-time student group. It can be said that leaving high school does produce well-being advantages, and at least no well-being disadvantages, for most students no matter what occupational situation they select. This was not the case for career decision-making selfefficacy, which showed no change. Patton and Creed (2001) found career decision-making self-efficacy to be stable across the later years of high school. The present study indicates that this stability persists post-school. The students with the poorest career decision-making self-efficacy were those in the labour force without full-time employment. These young people would benefit from interventions targeted at improving this important career-related variable, which could be delivered while they were at school or after they have entered the labour market (see Prideaux, Creed, Muller, \& Patton, [2000] for review of career interventions).

\section{Examination of groupings at $T 1$}

When the groups that were formed at $\mathrm{T} 2$ after leaving school were examined at $\mathrm{T} 1$, a number of differences were identified. Students who continued on to full-time study had fewer paid work experiences than all of the other groups. This may reflect a socio-economic status dimension, with those who have less of a need to work while at school more likely to continue with further education and to not have to work while undertaking this. However, while it has been claimed that paid work experience when at school does contribute to personal development and enhance work habits (for a review see Mortimer \& Johnson, 
1998), the present study suggests that it is negatively associated with continuation to further full-time study.

Differences were also found among the groups for self-reported school achievement, with those who continued on as full-time students with paid work reporting higher levels than both the full-time employed and those in the labour market without full-time work. This is consistent with other research that has identified low achieving adolescents as more likely to dropout of school (Newcomb, Abbott, Catalano, Hawkins, Battin-Pearson, \& Hill, 2002) and to have more difficulty when in the labour market (Creed, 1999). In this study, students who reported lower levels of achievement were less likely to continue with their formal education.

Lastly, there was a trend for differences in psychological distress, with the full-time students with paid work and the full-time employed reporting lower levels than those in the labour market without full-time work. These results suggest that those students who achieved poorest occupationally were disadvantaged in relation to well-being whilst at school. It cannot be determined whether this group of students was especially disadvantaged by their experience of their final high school year, or whether they experience a longer-term disadvantage. This needs to be further examined in prospective studies that begin earlier than the current study. What it does suggest is that interventions for occupationally disadvantaged youth, which have focused on well-being and work related variables (see Creed, Machin, \& Hicks, 1999) may need to be targeted earlier while students are still at school. The evidence here also favours a "drift" hypothesis in relation to post-school occupational status, with the more disadvantaged students at school being predisposed to occupational disadvantage before they enter the labour market. 


\section{Conclusion}

This study has demonstrated that well-being and career-related confidence are affected by the act of leaving high school, that these variables are influenced post-high school by the occupational situation the student selects, but that pre-existing levels of well-being and confidence influence levels post-high school. There is support here for both the drift and social causation hypothesis, which implies that pre-existing dispositions lead students to select or be directed towards a particular path, but that the occupational situation chosen impacts on well-being and confidence in situ. There is evidence that the students who left school to join the labour market but failed to find full-time employment were disadvantaged compared with the other groups in relation to well-being and confidence. This disadvantage was evident while the students were still at school and when they had left school. The challenge here is for school-based practitioners to be able to identify these at-risk students and provide interventions that not only improve well-being and confidence while at school but provide occupational-related skills (e.g., job search) that will be useful to them in their transition from school to work. The other group that was relatively disadvantaged in relation to well-being were the full-time students. This group reported the least amount of paid parttime work while still at school. The role of part-time employment while at school needs to be examined for its effect on well-being, as it has been examined for its capacity to foster personal development and work skills acquisition. It is also possible that these students who have chosen further study, and do not need or intend to work as well as study have particular demands that contribute to poorer well-being, which needs to be acknowledged and addressed. Lastly, wider longitudinal studies are needed to determine how early these at-school disadvantages emerge and how they impact on education and other life processes than occupational choice. 


\section{References}

Bandura, A. (1986). Social foundations of thought and action: A social cognitive theory. Englewood Cliffs, NJ: Prentice-Hall.

Banks, M. H., Clegg, C. W., Jackson, P. R., Kemp, N. J., Stafford, E. M., \& Wall, T. D. (1980). The use of the General Health Questionnaire as an indicator of mental health in occupational studies. Journal of Occupational Psychology, 53, 187-194.

Banks, M. H., \& Henry, P. (1993). Change and stability in employment commitment. Journal of Occupational and Organizational Psychology, 66, 177-184.

Betz, N. E., \& Hackett, G. (1986). Applications of self-efficacy theory to understanding career choice behavior. Journal of Social and Clinical Psychology, 4, 279-289.

Betz, N. E., Klein, K. L., \& Taylor, K. M. (1996a). Career Decision-making SelfEfficacy: Short Form. Columbus, OH: Ohio State University, Department of Psychology.

Betz, N. E., Klein, K. L., \& Taylor, K. M. (1996b). Evaluation of a short form of the Career Decision-making Self-Efficacy Scale. Journal of Career Assessment, 4, 47-57.

Betz, N. E., \& Voyten, K. K. (1997). Efficacy and outcome expectations influence career exploration and decidedness. The Career Development Quarterly, 46, 179-189.

Blascovich, J., \& Tomaka, J. (1991). Measures of self-esteem. In J. P. Robinson, P. R. Shaver, \& L. S. Wrightsman (Eds.), Measures of personality and social psychological attitudes. Vol. 1. London: Academic Press, 115-160.

Blustein, D. L. (1989). The role of goal instability and career self-efficacy in the career exploration process. Journal of Vocational Behavior, 35, 194-203.

Broomhall, H. S., \& Winefield, A. H. (1990). A comparison of the affective well-being of young and middle-aged unemployed men matched for length of unemployment. British Journal of Medical Psychology, 63, 43-52. 
Creed, P. A. (1999). Predisposing factors and consequences of occupational status for long-term unemployed youth: A longitudinal study. Journal of Adolescence, 22(1), 81-93.

Creed, P. A., \& Evans, B. (In press). Personality, well-being and deprivation theory. Personality and Individual Differences.

Creed, P. A., \& Machin, M. A. (2002). Access to the latent benefits of employment for unemployed and underemployed individuals. Psychological Reports, 90, 1208-1210.

Creed, P. A., Machin, M. A., \& Hicks, R. (1999). Improving mental health status and coping abilities for long-term unemployed youth using cognitive-behaviour therapy based interventions. Journal Organisational Behavior, 20, 963-978.

Creed, P. A., Muller, J., \& Machin, M. A. (2001). The role of satisfaction with occupational status, neuroticism, financial strain and categories of experience in predicting mental health in the unemployed. Personality and Individual Differences, 30, 435-447.

Crites, J. O. (1961). A model for the measurement of vocational maturity. Journal of Counseling Psychology, 8, 255-259.

Dooley, D., Catalano, R., \& Hough, R. (1992). Unemployment and alcohol disorder in 1910 and 1990: Drift versus social causation. Journal Occupational and Organizational Psychology, 65, 277-290.

Evans, S. T. (1986). Variations in activity and psychological well-being in employed young adults. Unpublished doctoral dissertation, University of Manchester.

Evans, S. T., \& Banks, M. H. (1992). Latent functions of employment: Variations according to employment status and labour market. In C. H. A. Varhaar \& L. G. Jansma (Eds.). On the mysteries of unemployment (pp. 281-295). Dordrecht, Netherlands: Kluwer Academic. 
Evans, S. T., \& Haworth, J. T. (1991). Variations in personal activity, access to categories of experience and psychological well-being in unemployed young adults. Leisure Studies, 10, 249-264.

Feather, N. T. (1990). The psychological impact of unemployment. New York: SpringerVerlag.

Feather, N. T., \& O'Brien, G. E. (1986). A longitudinal study of the effects of employment and unemployment on school leavers. Journal of Occupational Psychology, $59,121-144$.

Gianakos, I. (1999). Patterns of career choice and career decision-making self-efficacy. Journal of Vocational Behavior, 54, 244-258.

Goldberg, D. P. (1972). The detection of psychiatric illness by questionnaire. London: Oxford University Press.

Goldberg, D. \& Williams, P. (1988). A user's guide to the General Health Questionnaire. England: The NFER-NELSON Publishing Company Ltd.

Gurney, R. M. (1980). Does unemployment affect the self-esteem of school-leavers? Australian Journal of Psychology, 32(3), 175-182.

Hackett, G., \& Lent, R. (1992). Theoretical advances in career psychology. In S. Brown \& R. Lent (Eds.), Handbook of counseling psychology ( $2^{\text {nd }}$ ed.). New York: Wiley.

Hammarström, A., \& Janlert, U. (1997). Nervous and depressive symptoms in a longitudinal study of youth unemployment - selection or exposure? Journal of Adolescence, 20(3), 293-305.

Jahoda, M. (1981). Work, employment and unemployment: Values theories and approaches in social research. American Psychologist, 36, 184-191.

Jahoda, M. (1982). Employment and Unemployment: A Social-psychological Analysis. London: Cambridge University Press. 
Lent, R. W., \& Hackett, G. (1987). Career self-efficacy: Empirical status and future directions. Journal of Vocational Behavior, 30, 347-382.

Luzzo, D. A. (1995). The relative contributions of self-efficacy and locus of control to the prediction of career maturity. Journal of College Student Development, 36, 61-66.

Miles, I. (1983). Adaptation to unemployment. Science Policy Research Unit. Brighton: University of Sussex.

Morrell, S., Taylor, R., Quine, S., Kerr, C., \& Western, J. (1994). A cohort study of unemployment as a cause of psychological disturbance in Australian youth. Social Science and Medicine, 38(11), 1553-1564.

Mortimer, J. T., \& Johnson, M. K. (1998). New perspectives on adolescent work and the transition to adulthood. In R. Jessor (Ed.). New perspectives on adolescent risk behavior (pp. 425-496). New York: Cambridge University Press.

Muller, J., Hicks, R., \& Winocur, S. (1993). The effects of employment and unemployment on psychological well-being in Australian clerical workers: Gender differences. Australian Journal of Psychology, 45, 103-108.

Murphy, G. C., \& Athanasou. (1999). The effect of unemployment on mental health. Journal of Occupational and Organizational Psychology, 72, 83-99.

Newcomb, M. D., Abbott, R. D., Catalano, R. F., Hawkins, J-D., Battin-Pearson, S., Hill, K. (2002). Mediational and deviance theories of late high school failure: Process roles of structural strains, academic competence, and general versus specific problem behavior. Journal of Counseling Psychology, 49(2), 172-186.

Patton, W., \& Creed, P. A. (2001). Developmental issues in career maturity and career decision status. The Career Development Quarterly, 49, 336-351. 
Prideaux,, L., Creed, P. A., Muller, J., \& Patton, W. (2000). A review of career interventions from an educational perspective: Have investigations shed any light? Swiss Journal of Psychology, 59(4), 227-239.

Rosenberg, M. (1965). Society and the adolescent self-image. Princeton, N.J.: Princeton University Press.

Rowley, K., \& Feather, N. (1987). The impact of unemployment in relation to age and length of unemployment. Journal of Occupational Psychology, 60, 323-332.

Shanahan, M., Mortimer, J., \& Krueger, H. (2002). Adolescent and adult work in the twenty-first century. Journal of Research on Adolescence, 12(1), 99-120.

Tabachnik, B. G., \& Fidell, L. S. (1996). Using Multivariate Statistics. New York: HarperCollins College Publishers.

Warr, P. B. (1987). Work, unemployment and mental health. Oxford: Oxford University Press.

Warr, P. B., \& Jackson, P. R. (1987). Adapting to the unemployed role: A longitudinal investigation. Social Science and Medicine, 25, 1219-1224.

Waters, L. E. \& Moore, K. A. (2001). Coping with economic deprivation during unemployment. Journal of Economic Psychology, 22, 461-482.

Waters, L. E. \& Moore, K. A. (2002). Reducing latent deprivation during unemployment: the role of meaningful leisure activity. Journal of Occupational and Organizational Psychology, 75, 15-32.

Watson, D., \& Clark, L. A. (1997). Extraversion and its positive emotional core. In R. Hogan, J. Johnson \& S. Briggs (Eds.). Handbook of personality psychology, (pp. 767-793). San Diego: Academic Press. 
Whelan, C. T. (1992). The role of income, life-style deprivation and financial strain in mediating the impact of unemployment. Journal of Occupational and Organizational Psychology, 65, 331-344.

Winefield, A. H. (1995). Unemployment: Its psychological costs. In C. L. Cooper \& I. T. Robertson (Eds.). International Review of Industrial and Organizational Psychology. Chichester: Wiley.

Winefield, A. H., \& Tiggemann, M. (1985). Psychological correlates of employment and unemployment: Effects, predisposing factors and sex differences. Journal of Occupational Psychology, 58, 229-242.

Winefield, A. H., Tiggemann, M., Winefield, H. R., \& Goldney, R. D. (1993). Growing up with unemployment: A longitudinal study of its psychological impact. London: Routledge. 